wards, as well as for those not quite so large, which are so peculiar in form (as occasionally, but very rarely, happens) that the lithotrite fails to grasp or retain them? I think there is no doubt about the answer-viz., that it is the suprapubic and not the lateral position." And again: "Finally, I think I am quite justified in believing that unless the operator has had a large experience of lithotrity (and there are not many of whom this can be affirmed), the high operation would generally be a safer proceeding than crushing for a calculus which is hard and much above an ounce in weight." In regard to the danger of impotence from peritoneal section, to which I alluded in my paper above mentioned, I am permitted to quote the following extract from a private letter received from my friend, Dr. A. H. Haemstadt of Pottsville, Pa.-a lithotomist of large experience: "Your eleventh accident-impotence-is well put; only one of eighteen whom I cut as boys, grown to manhood and married, has had issue as far as I can learn."

One of the strongest arguments in favour of the suprapubic operation is that it avoids all interference with the genital organs, thus preventing the so frequent reflex disturbance of the nervous system accompanying the introduction of instruments through the urethra-a practical point to which, I believe, I was the first to publicly invite attention. I am, Sir, yours truly,

W. G. TREMaINE, M.D.,

Major and Surgeon, U.S. Army ; Surgeon-in-Chief, Buffalo Sisters' Hospital, \&c.

Buffalo, N.Y., Feb. 15̆th, 1886.

\section{PASTEUR'S EXPERIMENT.}

\section{To the Editor of THE LANCET.}

Srr,-In your leader of March 20th, and in the special article in THE LANCET of last week, which are devoted to a description of the method by which M. Pasteur secures and uses the protective virus, the attention of the medical profession is intelligently drawn to a subject of great interest and importance. For the moment M. Pasteur is concerned with hydrophobia alone, but the issues presented to the mind of anyone who has become practically acquainted with the inception and progression of disease are many and far-reaching. It may be said of all disease that the period of active pathological change is preceded by a period of passive fermentation, which prepares the whole animal structure for the consequent and more perceptible morbid process. At present, however, this period of latency in the majority of diseases cannot be exactly determined, and, indeed, the conditions and circumstances of disease, regarded as they are at present under the somewhat uncertain light of our knowledge, are strangely various and bewildering. Perhaps, if the jaded general practitioner of medicine, careful and troubled like Martha about many things, were to express his mind freely concerning the mysterious vagaries of his many-faced adversary, Virgil's unkind description of the gentler sex-

$$
\text { "Varium et mutabile semper femina "- }
$$

would, with a trifling alteration, suit his purpose best. There are, however, certain diseases in which the period of incubation can be exactly determined, and in other cases by careful and long-continued observation the scientific physician has arrived at conclusions which are found to be erroneous only in exceptional cases. M. Pasteur proposes to deal with a disease during its incubation period, and has selected a disease which is "only conveyed by direct contagion, so that the date of the introduction of the poison into the system can be fixed with precision." (THE LANCET, March 20th). At present M. Pasteur proposes merely to inoculate persons who have been bitten by mad dogs, but, as you say in the leader from which I have already made a quotation, "in process of time it may become the fashion to inoculate with the mitigated virus in order to give protection against the possible bites of mad dogs, but at present there seems littie likelihood of this practice being established, nor, on the whole, is it, desirable." The practice would not, in my opinion, be desirable, because hydrophobia is a disease of the lower animals, and is only occasionally transferred from them to man; but if $M$. Pasteur succeed in his experiment, it might become desirable that all dogs should be protected by inoculation. By his brilliant discovery Jenner drove out from the midst of the people a terrible and deeply-rooted disease. In like manner M. Pasteur may succeed in removing from the animal world the disease against which his scientific labours have been for some time directed. If success should attend his efforts-and at present there is little reason for anticipating failure--a great advance will have been made in the preventive treatment of disease. I may be too sanguine in expressing my belief that the experiment which is proceeding at Paris is a swift. approach towards the clear noonday of scientific medicine of which Jenner's discovery is the brilliant dawn. There is certainly ample reason to be found for the belief in the success which has attended the theory of vaccination in practice, and in the patient and questioning industry of the great French pathologist and chemist. $\mathrm{He}$ is indeed a. worthy successor of his countryman, Lavoisier, who, dragged down with many others into the ruthless whirlpool of the first Revolution, asked for a fortnight more of life in which to finish an experiment.

In speaking of M. Pasteur and his experiment, one is led naturally enough to consider the manner in which it has been received by those who are opposed to science on purely sentimental grounds, and by those who, with varying degrees of responsibility, take part in the government of the country. In a recent and very admirable work SirHenry Sumner Maine arrives at the somewhat sad conclusion that science will suffer under a government by the people. I have mentioned Lavoisier and his pathetic request, but, as Carlyle says, "the Republic had no use for experiments," and so the fortnight more of life was denied to the chemist. We have not yet descended to the depth of moral and social dissolution to which the French people were dragged by Robespierre, Marat, and company, but we are hurrying on at a startling pace, and only the other day, at the call of a shrill and shallow sentiment which would send all science to the winds, the Contagious Diseases Acts were removed from the Statute Book. "The day of checks and counterpoises is over," exclaimed Mr. Labouchere some time ago in the Fortnightly Review, and the present House of Commons is showing that there is some truth in the exclamation. "Government by the people for the people" (this is the formula I think) will mean a paralysis of scientific effort. True science can never be popular in the ordinary acceptation of the word. Unlike Radicalism, it does not promise well on the surface, and does not leap from a chaos of improbable and indefinite premisses to timeserving and popular conclusions. The best and most useful part of scientific work is hidden from the notice of the multitude. The days of earnest endeavour towards the practical attainment of a great scientific end are unheard of by the busy throng who thrive unthinkingly upon the discoveries that the votaries of science have made. At present we may congratulate ourselves that we are yet some distance from a government by the people, and rejoice in the fact that in spite of the absorbing Irish problem, a Governmental commission is to be appointed to investigate into the subject upon which M. Pasteur is experimenting The names which you mention are of themselves sufficient to satisfy those interested that the work will be done in a thoroughly efficient fashion. Scientific investigation of the severest kind must always be applied to every discovery of moment, and in the instance of M. Pasteur's experiment the discovery is of the first importance. For my part, I believe that investigation will but prove the truth of the theory by making sure its practical success.

Glasgow, March 30th, 1886 I am, Sir, yours truly,

\section{HEALTH-RESORTS FOR PHTHISICAL PATIENTS.}

\section{To the Editor of THE Lancer.}

Sin,-I read with much pleasure in your issue of March 13th a leading article on Health-resorts for Phthisis. $\mathrm{My}$ purpose in writing now is to endorse, with what weight an experience of twenty-two years' practice in Sydney may carry, the truth of your remarks, in so far as they relate to Australia. I have frequently expressed to my medical friends here, and in words almost identical with your own, the great importance of warning consumptive patients, when contemplating removal to New South Wales, against taking up their residence in Sydney or any other place upon the eastern seaboard. During nine months of the year the atmosphere is warm and moist, and the surroundings highly detrimental to the phthisical invalid. Tubercular deposit rapidly undergoes softening, and night sweats, loss 
of tlesh and appetite, with sometimes diarrhœa, ensue. How different, as a rule, the progress of the patient who has been wisely advised to betake himself to the great inland plains, where the air is dry and warm. Living in a town, or, far better, on a sheep or cattle station so situated, he gains flesh, his appetite returns, night sweats cease, and life becomes enjoyable. My case-books afford abundant evidence of cures so brought about. Even when cure has not been effected life has been greatly prolonged. To a young and, as is so often found in the phthisical, a highly intelligent mind continuous absence from the metropolitan centres of southern civilisation is often a sore trial and has a depressing effect. Fortunately my experience enables me to say that an exception to the rule of unbroken residence on the inland plains may be made during the winter quarter. At this season the climate in Sydney is dry and bracing, the very opposite condition to that which exists during the other nine months. I have been in the habit, therefore, of permitting my consumptive patients to visit Sydney during the winter, and when the privilege has not been abused the change of scene and distraction from thei own sensations have proved advantageous to them. With this exception, however, it cannot be too strongly urged that phthisical patients should reside permanently upon the inland plains, which are at an elevation of from two to three thousand feet above the sea level.

I am, Sir, yours faithfully,

Sydenham-hill, March 30th, 1886. P. SYDNEY JONES.

UNUSUALLY PROLONGED PERIOD OF INCUBATION OF SMALL-POX.

\section{To the Editor of THF $\mathrm{LANCET}_{\text {. }}$}

SIR,-The following case of exceptionally long incubation of small-pox appears worthy to be put on record. The proof that the patient was but once exposed to infection, and that only for two hours and a half, is about as strong as available proof on such a matter is likely to be, inasmuch as, until the occurrence of the case in question, there has been no small-pox in Newcastle for above half a year, the last case before this having been notified in July, 1885; neither has the patient been anywhere outside of Newcastle, or in known communication with any infected person except one, or with any other person coming from an infected place. The circumstances are :-

Mrs. A. B- - first began to feel unwell on Friday, the 26th of March. A very sparse eruption of small-pox papules appeared on the 29th (fourth day of illness). On March 6 th the patient's brother, T. S- was discharged from a small-pox hospital upwards of thirty miles distant from here, and came to Newcastle to the house of his sister on the same day. He remained with her for two hours and a half, when he went away by the north train, leaving behind him none of his clothing or other belongings. No communication between the two has taken place since. There is therefore, good reason to believe that in this case the period of incubation extended from the 6th to the 26th of March inclusive, or in all twenty-one days. The patient bears faint vaccination cicatrices from infancy, equal in area to about six ordinary vaccine vesicles. It would be interesting to know how far the incubative stage has been affected by these. -I am, Sir, yours obediently,

HenRy E. Armstrong,

Medical Offlcer of Health, Medical Supt., Newcastle

Newcastle-on-Tyne, April 6th, 1886. Small-pox Hospital, \&c.

\section{BIRMINGHAM.}

\section{(From our own Correspondent.)}

THE MEDICAL INSTITUTE.

THE annual meeting of the Medical Institute was held on the 25th ult., under the presidency of Mr. J. S. Gamgee. A portrait of the late Dr. Russell was presented by Mrs. Russell, and accepted with much satisfaction as a memento of the esteem with which the high personal character and professional attainments of Dr. Risssell are remembered by the members of the institute. The report shows that the library is increasing in popularity and usefulness, the circulation of books being more than 400 as compared with the numbers of the previous year. The financial position has improved somewhat, but still shows a deficit between the annual income and expenditure of a little less than $£ 50$. To meet this and a bank overdraft of $£ 108$ the Committee show good security, but feel that the prospects of the institute would be more encouraging if there was an absolute freedom from debt.

The third series of lectures have been well attended and well delivered. The interest manifested in these discourses has been well sustained and their success assured by the reputation and ability of the lecturer. The subjects have been such as to set an intelligent public thinking for themselves on the many problems associated with the more common ailments which affect the health and constitute the enjoyment or otherwise of daily life. After such teaching no reasonable excuse can be afforded for preferring the ignorance of bliss which is frequent among those who "enjoy" bad health.

\section{THE JAFFRAY SUBURBAN HOSPITAL.}

The 15th of March was a memorable day in the history of this young and promising branch, for it witnessed the transfer of the first detachment of patients from the parent institution. They were conveyed from the general hospital in ambulances and carriages, and on their arrival were at once placed in comfortable quarters in the pure atmosphere of their temporary home. Surrounded by plants, fiowers, pleasing pictures, and readable books, the bracing air and cheerfal adjuncts ought to produce palpable effects upon the chronic sufferers, and materally aid in restoring them to health and vigour. The value of this auxiliary to the older hospital will be immense, as it cannot fail to add to the prestige which the latter institution has accumulated during a period of more than a century in the cause of humanity.

THE WORKHOUSE INQUIRY.

As a result of the recent inquiry by the Local Government Board concerning the difference between the guardians andtheir senior medical officer, I regret to say that the authority has called for the resignation of the medical officer. It is difficult for outsiders to appreciate the merits of a dispute upon matters of discipline in technical details. The senior medical officer has held his position for a number of years, and has worked with zeal; that this has not been tempered with discretion is the opinion of the higher powers, and, like many good officials, he must yield with as good a grace as possible to the force of circumstances which he cannot coutrol.

\section{NORTHERN COUNTIES NOTES. (From our own Correspondent.)}

\section{GATESHEAD DISPENSARY.}

AT the annual meeting of the Gateshead Dispensary held recently, the resignation of $\mathrm{Dr} . \mathrm{Wm}$. Robinson was received and accepted with regret. Dr. Robinson, who has been appointed medical officer of health for the borough, has acted on the honorary staff of the dispensary for nearly thirty years. The Committee passed a hearty vote of thanks for his long and valuable services. It was mentioned in the report presented by Dr. Hardy at the same meeting, that the work of the year had compared favourably with that done in previous years. The number of patients under treatment at the date of the last report was 221 . This, with 2912 admitted during the year, makes the total number of letter-patients treated 3133 , as compared with 2815 in the previous year. The letter patients consist of 2620 home patients and 513 out-patients. The number of casuals was 9841 , this being made up of 290 accidents, teeth extractions, and 8898 medical cases. The casualty patients of the year before were 10,003 , and notwithstanding that the twopenny system has been carried out during the whole year the number has been practically maintained. During two or three months of the year a severe epidemic of measles was experienced; this was also followed by a slight one of scarlet fever, but the dispensary patients had been entirely free from the more severe forms of zymotic disease. The Samaritan fund had been of great service, and was largely drawn upon. It may be mentioned that the charge of twopence for the casualty patients had yielded 